\title{
PSYCHOLOGICAL AND PEDAGOGICAL ASPECTS OF THE EDUCATIONAL PROCESS IN RUSSIA
}

\author{
Bogdan Ershov ${ }^{1}$, Olga Shmyreva ${ }^{2}$ \\ ${ }^{1}$ Doctor of Historical Sciences, Professor, Voronezh State Technical University, 20 years of \\ October street, 84, Voronezh, Russia, E-mail: bogdan.ershov@yandex.ru \\ ${ }^{2}$ Candidate of Psychological Sciences, Associate Professor, Voronezh State University of \\ Engineering Technologies, Revolutsii street, 19, Voronezh, Russia, \\ E-mail: oishmyreva@rambler.ru
}

\begin{abstract}
The current stage of the development of professional education is characterized by the desire to penetrate into the very foundations of the process of humanitarization, systematically and organically integrate the humanities into the curricula and curricula, as well as to identify the possibilities of various disciplines for the humanization of education. By humanitarization, we mean not just the saturation of the curriculum with courses of a humanitarian nature, but the formation of students need to assimilate world culture in order to merge into a single whole the cognitive-activity, moral-ethical and aesthetic components of personal development by means of general theoretical and special disciplines. The importance of scientific research in this area is determined by the need to develop and justify a strategy for the development of domestic education in the context of modernization and reform of various parts of the education system.
\end{abstract}

Keywords: education, upbringing, state, science, university.

\section{INTRODUCTION}

In the study, we proposed a model of a humanitarian educational environment created directly in the study of individual academic disciplines. With regard to a specific academic subject, the humanitarian educational environment is a personality-oriented educational process based on a set of specially organized psychological and pedagogical learning conditions, aimed at revealing the humanitarian specifics of the studied area of knowledge, comprehensively realizing the humanitarian potential of the studied specific scientific discipline through the inclusion of specially organized personally significant knowledge for the student and the use of ergonomic and comfortable pedagogical technologies, supported by a set of organizational, methodological, psychological measures that ensure the formation of an integral humanitarian culture. At the same time, the degree of focus of the educational process on the development and self-development of the personality of students, including professionally important personality traits, has been significantly strengthened.

\section{METHODOLOGY}

The study used a complex of interpenetrating and complementary research methods that are adequate to the nature of the phenomenon being studied, the goal, the subject of research, and also the formulated tasks. It included: theoretical analysis of the development of social systems (historical - retrospective, comparative methods); predictive methods (modeling of social and pedagogical processes, expert assessments, generalization of independent characteristics); construction of logical schemes of research analysis; observational methods (direct and indirect observation); experimental methods (ascertaining, 
forming, diagnostic variants of the experiment); qualitative and quantitative methods of analysis, mathematical methods of processing experimental results; statistical and humanitarian approaches in the study of social reality.

\section{DISCUSSION}

The idea of humanitarization has found its practical embodiment in the curricula of universities of technical and natural science orientation, as well as in the process of training specialists in the conditions of university education. To date, certain aspects of training specialists have been disclosed by means of teaching a cycle of humanitarian disciplines (M.V.Semyshev), building a model of a humanitarian educational environment (V.A.Kozyrev), psychological and pedagogical conditions for the implementation of the humanistic orientation of higher pedagogical education (N.I. Kuznetsova, Yu.V. Senko), the content and didactic - technological aspects of the humanitarization of the educational process are analyzed (ZG Suleimanova); the problems of constructing a general humanitarian basis of modern education by means of teaching general and special disciplines (T.M. Elkanova, A.Yu.Belogurov) are revealed, theoretical and applied aspects of training pedagogical personnel of the regional education system (Z.K. Kargieva).

\section{RESULTS}

Conceptually-theoretically and specifically-meaningfully developed in the study, the concept of creating a humanitarian educational environment by means of general theoretical and special disciplines includes the following components: ethical-axiological, historical-generalized, philosophical-methodological, integrativeapplicative, interaction-gnostic, sensitive-reflexive, ecological-activation, anthropocentric, creative and developmental, informational, personality-variative, contemporary-presentational, regional-ethnic, culturalinfusional.

We see the main task of the humanization of education in the study of foreign languages in the introduction of students into the historical, cultural and value context of social phenomena, the development of science and civilization; setting algorithms for considering and analyzing facts and phenomena from a humanistic point of view; showing the basic laws of the development of science and culture, as the most complex spheres of human activity, etc. The most important task of the humanization of vocational education is also the formation of an integral structure of value-semantic attitudes that determine the mentality of a future specialist, through the prism of which there is an awareness of a rapidly changing world and a person's place in it; the development of a value-semantic attitude to each problem (global or local, mass or individual), a vision of its inner human meaning, an understanding of its positive (or destructive) consequences; development of such intellectual and personal qualities as openness to new things, tolerance, understanding of the versatility of the surrounding world, its ambiguity.

In an experimental mode, the method of didactic modeling was applied, and the harmonization of the program-targeted and problem-oriented approaches was carried out, which made it possible to take into account the experience of the development of education in the past and improve it taking into account modern realities.

The humanization of higher education should be of a systemic multilevel nature. The system-forming component of this process is the technology of the formation and development of a general and humanitarian culture in a student based on the relationship that exists between knowledge (cognitive aspect) and experiences (emotional-value aspect). The influence of the methods and forms of educational work used in the pedagogical process on the development of the personality traits of a student is explained by interfunctionality, which links individual psychological phenomena and changes with a whole complex of changes in the external and internal environment.

In the conditions of the national republics of the Russian Federation, the formation of a multilingual personality that has absorbed the values of native, Russian and foreign cultures and is ready for intercultural communication is of particular importance. The combination of regional and basic components contributes to a more effective formation of the humanistic self-awareness of students and the development of a system of fundamental value orientations and moral principles. At the same time, there is a process of semantic axiological filling of the content of education, its enrichment with humanistic ideas, concepts, moral guidelines and values that cause emotional experiences and contribute to the formation of an active life position.

In the study, we develop and implement a structure for the formation of a future specialist's readiness for intercultural communication, which consists of the following components: socio-cultural, cognitive-activity, situational-reflexive, multicultural-worldview. 
The analysis of the results allowed us to see the dynamics of each of the indicators among the students of the experimental group, which allows us to conclude about the effectiveness of the proposed approach (the increase was on average 30-40\%). In addition, the motivation of students to master knowledge significantly increased, which was reflected in the level of their preparation in the subject.

\section{CONCLUSION}

In the context of the emerging planetary civilization, humanization acts as a strategic guideline for the development of modern higher education, which is associated with the society's awareness of the priorities of the humanitarian worldview and the need to rethink the role of education in solving global problems of humanity, Russian society and each person individually. The search for effective pedagogical tools of an instrumental, cultural, axiological and personality-developmental nature is associated with the humanization of education. The essence of the humanization of education lies in the formation of a style of thinking and activity focused on the development, development and use of any knowledge as a means of humanizing life.

The interaction of the processes of humanization and humanization of education is determined by the fact that each of the concepts under consideration is separated from the other and at the same time associated with it, since these separates and connections are mutually necessary postulates. The humanization of higher professional education is a "technology", a psychological and pedagogical mechanism, methods and means of humanizing the entire system of the educational process. Humanization is the process of forming a common culture, and this culture is a measure of the development of a person himself, a characteristic of the qualitative aspect of any human activity, its unity and integrity. Based on the foregoing, the humanitarization of education can be defined as a directed pedagogical process that ensures the formation and development of a holistic personal attitude to reality with an emphasis on motivational and evaluative processes, in which the actualization of the acquired professional knowledge of a specialist is not neutral, but is carried out in accordance with clearly expressed morally - value, moral criteria.

\section{REFERENCE LIST}

Agafonova M.S. (2007) Economic relations of a firm with various entities. Journal of Economic Theory. Number 4. 9. (in Russ).

Agafonova M.S. (2008) Formation of a firm's external economic relations. Bulletin of the Russian State Pedagogical University. A.I. Herzen. № 49. (in Russ).

Agafonova M.S. (2008) Formation of external economic relations of a company. Bulletin of the Russian State Pedagogical University named after A.I. Herzen. №. 49. (in Russ).

Demyanov A.A. (2010) Justification of the appropriateness of multi-step exposure to destabilizing factors and risks. National interests: priorities and security. Number 10. (in Russ).

Dengov, V.V. Microeconomics in 2 vols. T. 1. (2018) Theory of consumer behavior. Theory of the company. Theory of markets: a textbook for undergraduate, specialty and master's degrees. 410 p. (in Russ).

Efimiev A.S., Lavrinenko Y.B. (2019) Global companies in the digital economy. FES: Finance. Economy. T. 16. No. 6. P. 39-42. (in Russ).

Efimiev A.S., Provotorov I.A., Vorotyntseva A.V., Elshammari H.F.M. (2019) Systematization of barriers and limitations for innovation. Financial economics. №. 8. Pp. 353-355. (in Russ).

Ershov B.A. (2010) The Russian Orthodox Church and secular power in the Voronezh province in the XIX early XX centuries. GOU VPO "Voronezh State Technical University". Voronezh. 167 p. (in Russ).

Ershov B.A. (2010) The system of spiritual education in Voronezh province in the 19th century. Education and Society. №. 5 (64). Pp. 105-108. (in Russ).

Ershov B.A., Fursov V.N. (2018) The Russian Church in the State Mechanism of Russia. Bulletin SocialEconomic and Humanitarian Research. № 1. Pp. 32-37. (in Engl).

Ershov B.A., Perevozchikova L.S., Romanova E.V. (2019) Globalization and Intensification of Spiritual Values in Russia in the Philosophical Aspect. 6th International Conference on Education and Social Sciences Abstracts \& Proceedings. Pp. 208-212. (in Engl). 
Ershov B.A., Perevozchikova L.S., Romanova E.V., Ashmarov I.A. (2019) The Concept of Spirituality in Social Philosophy. Smart Innovation, Systems and Technologies. T. 139. Pp. 688-694. (in Engl).

Gumba H.M., Efimiev A.S., Uvarova S.S., Vorotyntseva A.V. (2019) Methodological approach to the analysis of the factor space of the innovative development of construction enterprises by modeling ranking distribution. Economics and Entrepreneurship. No. 5 (106). Pp. 1225-1231. (in Engl).

Okolelova E.Yu. (2006) Sustainability of economic processes and assessment of their predictability. Bulletin of Tula State University. Series: Construction, architecture and restoration. Pp. 146-151. (in Engl).

Okolelova E.Yu., Ryabinina V.S. (2017) Planning and forecasting as part of an enterprise financial strategy. Innovative economy: prospects for development and improvement. №. 5 (23). Pp. 109-114. (in Engl).

Romanova E.V., Perevozchikova L.S., Ershov B.A. (2017) The Lifestyle of the Human Being in the Information Society. 3rd International Conference on Advances in Education and Social Sciences Proceedings of ADVED Pp. 950-954. (in Engl).

Tkachenko M.F. (2011) Global challenges for the global labor market. World economy and international relations. 2011. № 9. (in Engl). 